\title{
Reproductive Characteristics of the Selected Cocoa (Theobroma cacao L.) Clones after Regenerated from the Somatic Embryogenesis Culture
}

\author{
Gibson Entuni ${ }^{1, *}$, Hollena Nori ${ }^{1}$, \\ Rebicca Edward ${ }^{1}$ and Ahmad Kamil bin Mohammad Jaafar ${ }^{2}$ \\ ${ }^{I}$ Faculty of Resource Science and Technology, Universiti Malaysia Sarawak, 94300 Kota Samarahan, \\ Sarawak, Malaysia \\ ${ }^{2}$ Malaysian Cocoa Board, Cocoa Research and Development Centre, Biotechnology Park, \\ 94300 Kota Samarahan, Sarawak, Malaysia
}

('Corresponding author's e-mail: gibsonentuni@gmail.com)

Received: 15 August 2020, Revised: 30 May 2021, Accepted: 15 June 2021

\begin{abstract}
This study was conducted to evaluate the reproductive characteristics of 4 elite cocoa clones (MCBC1, PBC230, KKM22 and KKM4) propagated via somatic embryogenesis culture. From the findings, all clones have similar reproductive characteristics with clones from conventional grafted. However, only KKM4 clone from immature zygotic embryo culture produced the shortest staminode to style distance of $1.83 \mathrm{~mm}$. This consequently influenced flower stability by reducing the efficiency of pollination by insects. It was found that this clone also has the highest number of flowers drop after anthesis ( 5 flowers) and lowest production of cherelle (5 cherelles). Further observation revealed that floral development from first bud visible (BBCH51) to flower anthesis (BBCH68) of all clones took around 31 days. These cocoa flowers which remained receptive soon after anthesis at 10 am (day-31) until the next day (day-32) suggesting 2 days' period of receptivity.
\end{abstract}

Keywords: Cocoa, Somatic embryogenesis, Reproductive, Pollination, Stigmatic receptivity

\section{Introduction}

Achieving an optimal pollination is crucial for the maximum yield in cocoa plant [1,2]. The cocoa plant produced flowers with various staminode to style distances with an average of between 0.05 to 3.00 $\mathrm{mm}$ [2]. According to Adjaloo et al. [2] the distance between staminode to style is one of a key factor for the successful fertilization of cocoa flowers after pollination process. The staminode to style distances of cocoa flowers were further classified into 3 types based on their arrangement. The type of a style to staminode was converging when their gap was less than $1.20 \mathrm{~mm}$ whereas parallel when their gap was between 1.21 to $2.40 \mathrm{~mm}$. The type of staminode to style was splay when their gap was above $2.41 \mathrm{~mm}$. From these, most of the cocoa flowers produced staminode separated from style by less than $2.00 \mathrm{~mm}$ [2].

According to Frimpong et al. [3] converging and parallel type of staminode to style distances are commonly observed and were also the most ideal flower spatial arrangements for the effective pollination in cocoa plant. This is because such distances offered an intimate contact and more accessible for the pollinating midges which have body size of around 1.00 to $2.00 \mathrm{~mm}$ for the deposition of pollen grains [3-5]. It is expected that more pollen grains will be extricated from the pollinator thorax onto the style of the receptive cocoa flowers. The converging and parallel type of staminode to style distances of flowers have been also reported gave the higher fruit set than splay type of staminode to style distance [6].

Apart from staminode and style distance, it is also crucial to study the flower reproductive development for the maximum yield in cocoa plant. Niemanak et al. [7] and Bridgemohan et al. [8] found that the phenological stages from flower to fruit development can be used to compute and predict the yield of cocoa plant. In addition, the stigmatic receptivity was also imperative in cocoa plant for sexual reproduction and seed formation [9]. This is because the timing and duration of stigmatic receptivity determined the pollination success where pollen grains will only be germinated during active receptive period of stigma [10]. In the other Theobroma species such as Theobroma subincanum, Souza et al. [11] observed that majority of the stigma started to become receptive in the morning of the first day after 
anthesis. In contrast, for Theobroma obovatum and Theobroma speciosum, Souza et al. [11] found that the optimal stigmatic receptivity for both species were in the evening of the first day after anthesis.

As all information on flower are important, it is necessary to assess any variation in the reproductive organ of the cocoa clones especially for those regenerated from the somatic embryogenesis culture since many plants have been found exhibited variation after regenerated through in vitro culture. The variations in tissue culture derived plants have been extensively reviewed by Bairu et al. [12]. In the present study, the reproductive characteristics of the somatic embryogenesis culture and grafted cocoa clones were quantified and compared for the presence of variation. Therefore, the reproductive characteristics evaluated were including the categorization of staminode and style distance, flower stability and pollination, floral developmental scale and stigmatic receptivity.

\section{Materials and methods}

Site description and plant material

The study was conducted in the field station at Malaysian Cocoa Board, Kota Samarahan, Sarawak, Malaysia during the main cocoa flowering season from January to March 2018. The soil in the field station is belong to Red Yellow Podzolic Soil (USDA) with $\mathrm{pH}$ of 5.76, phosphorus of $20 \mathrm{meq} / \mathrm{g}$, calcium of $5.1 \mathrm{meq} / \mathrm{g}$, magnesium of $3.0 \mathrm{meq} / \mathrm{g}$, potassium of $0.43 \mathrm{meq} / \mathrm{g}$ and cation exchange capacity of 0.45 $\mathrm{meq} / \mathrm{g}$. The soil has the A horizon consisted of clay loam texture, weak fine crumbly structure and friable to firm consistence whereas the B horizon consisted of clay only texture and firm consistence coarse sub angular blocky structure. During the flowering season, the monthly rainfall averaged $555 \mathrm{~mm}$ and temperature averaged $26.2^{\circ} \mathrm{C}$ (Table 1). The experiment was conducted based on 2 factors randomized complete block design of 4 type of cocoa clones from the Trinitario group which have high productivity and resistance to many pest and diseases (MCBC1, PBC230, KKM22 and KKM4) $\times 3$ type of propagation (immature zygotic embryo culture, staminode culture and grafting). There were 84 cocoa clones in total were regenerated according to a method developed by Adrianti [13]. The evaluation on all reproductive characteristics begun when the cocoa trees reached 21 months old following transplanting.

Table 1 The monthly mean rainfall $(\mathrm{mm})$ and temperature $\left({ }^{\circ} \mathrm{C}\right)$ at $\mathrm{MCB}$ Research Station, Kota Samarahan in 2018. The data was obtained from Malaysian Cocoa Board.

\begin{tabular}{|c|c|c|c|c|c|c|c|c|c|c|c|c|}
\hline & Jan & Feb & Mar & Apr & May & June & Jul & Aug & Sep & Oct & Nov & Dec \\
\hline Mean ${ }^{\circ} \mathrm{C}$ & 26.0 & 26.1 & 26.4 & 27.3 & 27.2 & 27.2 & 27.5 & 27.7 & 27.4 & 27.1 & 26.9 & 26.4 \\
\hline Rainfall & 669 & 559 & 436 & 277 & 255 & 240 & 194 & 219 & 231 & 317 & 345 & 505 \\
\hline
\end{tabular}

\section{Categorizations of staminode to style distance}

From each cocoa tree, 5 opened flowers that were still attached and another 5 fresh opened flowers that have dropped to the ground from the same tree were randomly collected for detail assessment [2]. The cocoa flowers were put into $300 \mathrm{~mL}$ glass jars with moistened cotton wool at the base to avoid them from withering. The distance between a style to 1 randomly selected staminode was measured in the laboratory under a stereomicroscope (Celestron S10-60, Columbia Street, Canada). The stereomicroscope allows a calibration of the images to the corresponding magnification by using Celestron MicroCapture Pro Software (Celestron, Columbia Street, Canada) (available online from https://www.celestron.com/pages/drivers-and-software). Based on the measurement, the flowers were classified into converging, parallel and splay (Table 2).

Table 2 The type of staminode to style distances of cocoa flowers [3].

\begin{tabular}{cc}
\hline Type of staminode to style & Style to staminode distance (mm) \\
\hline Converging & $\leq 1.20$ \\
Parallel & $1.21-2.40$ \\
Splay & $\geq 2.41$ \\
\hline
\end{tabular}




\section{Flower stability and pollination}

Ten flowers getting open (BBCH 60) [7] were randomly marked with waterproof paint from each cocoa tree. The flowers can be recognized by the presence of prominence grooves along the joined edges of sepals where they burst open [3]. The cocoa flowers that remained on the trees after $48 \mathrm{~h}$ were considered to have been pollinated [14]. To assess the flower stability among the regenerated cocoa clones, average number of opened flowers that has dropped within $48 \mathrm{~h}$ after anthesis and the number of pollinated flowers developed into young fruits were counted.

\section{Floral development scale}

The flower bud development was examined from each stem and jorquette branches of all cocoa trees. The observation was conducted daily at 10 am from January to March 2018 based on a modified version of $\mathrm{BBCH}$ (Biologische Bundesanstalt Bundessortenamt and $\mathrm{CHemische}$ Industrie) worldwide scale for cocoa plant. This development scale was generated by Bridgemohan et al. [8] and Niemanak et al. [7]. The length of time taken from first bud visible (FBV, BBCH 51) to the completion of bud growth (BBCH 59) was quantified in calendar days. The scale for phenological stage of flowering from first flowers getting open (BBCH 60 ) to $80 \%$ of flowers open (BBCH 68) was also described.

\section{Stigmatic receptivity}

For each cocoa tree, twenty flowers getting open (BBCH 60) were randomly marked with a waterproof paint. After fully opened (anthesis), the flowers were randomly collected for 2 days at every $10 \mathrm{am}$ and $5 \mathrm{pm}$ for the assessment of stigmatic receptivity. The flowers were placed on a glass slide with $3 \%$ Hydrogen Peroxide $\left(\mathrm{H}_{2} \mathrm{O}_{2}\right)$ for visual observation of stigmatic receptivity according to a method developed by Arenas Souza et al. [15] and Dafni [16]. The assessment of catalytic activity on the stigmatic surface was made based on the appearance of compact bubbles within $3 \mathrm{~min}$ in $25 \mathrm{~mL} \mathrm{H}_{2} \mathrm{O}_{2}$ solution. The intensity of stigmatic reaction was then categorised as low when the compact bubbles appeared less than $1 \mathrm{~min}$, moderate when the compact bubbles appeared between 2 to 3 min and high when the compact bubbles appeared more than $3 \mathrm{~min}$. The period of stigma receptivity was categorised into 2, i.e. active receptive period (ARP) measured by the presence of bubbles and passive receptive period (PRP) measured by the absence of bubble.

\section{Data analysis}

Data analyses were conducted using VassarStats online statistical computation (http://vassarstats.net) [17]. The means for each reproductive characteristic were reported and variation was established by Tukey HSD test at $p<0.05$. To evaluate the differences and interaction among cocoa clones and propagation type, a 2-Way ANOVA was performed.

\section{Results and discussion}

Categorizations of staminode to style distance

Majority of cocoa flowers produced parallel staminode ( $62 \%)$ while convergent staminode represented the least ( 12\%) (Table 3). Thus, most of the propagated clones in this study have an ideal staminode to style distance for the pollination process. According to Anin et al. [18], the staminode arrangements will affect the pollination success of cocoa flower. Compared with splay staminode, convergent and parallel staminodes would provide much more intimate contact between the pollinators and flower style. This will increase the chances for the deposition of pollen grains from pollinator's thorax onto the style. Hence, maximum number of cherelle will be produced from both convergent and parallel staminodes than splay staminode.

Table 3 The percentage of converging, parallel and splay type of staminode to style distances for all cocoa flowers from both wet and dry seasons in 2018.

\begin{tabular}{cc}
\hline Type of staminode relative to style & Percentage (\%) \\
\hline Converging & 11.4 \\
Parallel & 61.0 \\
Splay & 27.6 \\
\hline
\end{tabular}


The propagated cocoa clone has flowers with staminode to style distances averaged $\sim 2.10 \mathrm{~mm}$ (Table 4). The only exception was for KKM4 clone of immature zygotic embryo culture which have smaller staminode to style gap of $\sim 1.85 \mathrm{~mm}$. The difference suggested that this clone have undergone several changes in the genetic component during immature zygotic embryo culture process. It is expected that the changes have been expressed as an alteration in the stem to style distance. Nevertheless, such variation in flower characteristics have also reported in tissue cultured oil palm [19], strawberry [20] and extensively in the ornamental plants including roses, carnations, gerbera and orchids [21] which influenced their final productivity. The changes of genetic stability in crop plants following tissue culture was usually occurred due to some factors such as the source of explant, genotype, plant growth regulators and duration of culture [12].

Table 4 The distance of staminode to style for all cocoa flowers in wet and dry seasons.

\begin{tabular}{|c|c|c|}
\hline Cocoa clones & Propagation type & Staminode to style distance \\
\hline \multirow[t]{4}{*}{$\mathrm{MCBC1}$} & $\mathrm{ST}$ & 2.12 \\
\hline & $\mathrm{IZ}$ & 2.12 \\
\hline & $\mathrm{G}$ & 2.10 \\
\hline & Mean & 2.11 \\
\hline \multirow[t]{4}{*}{$\mathrm{PBC} 230$} & ST & 2.10 \\
\hline & $\mathrm{IZ}$ & 2.15 \\
\hline & $\mathrm{G}$ & 2.07 \\
\hline & Mean & 2.11 \\
\hline \multirow[t]{4}{*}{ KKM22 } & ST & 2.08 \\
\hline & $\mathrm{IZ}$ & 2.11 \\
\hline & $\mathrm{G}$ & 2.08 \\
\hline & Mean & 2.09 \\
\hline \multirow[t]{8}{*}{ KKM4 } & ST & 2.15 \\
\hline & $\mathrm{IZ}$ & 1.85 \\
\hline & $\mathrm{G}$ & 2.15 \\
\hline & Mean & 2.05 \\
\hline & $p$-value for propagation & 0.111 \\
\hline & Tukey HSD (5\%) & 0.06 \\
\hline & $p$-value for clones & 0.181 \\
\hline & Tukey HSD (5 \%) & 0.08 \\
\hline \multirow[t]{2}{*}{ Clones } & $p$-value for propagation*clones & $<0.001$ \\
\hline & Tukey HSD (5 \%) & 0.12 \\
\hline
\end{tabular}

ST, staminode culture trees; IZ, Immature zygotic embryo culture trees; G, Grafted trees; Tukey HSD, Tukey honestly significance difference.

\section{Flower stability and pollination}

Flower stability and pollination was influenced by cocoa clones $\times$ propagation type interaction. Only KKM4 clone from immature zygotic embryo culture observed with the maximum number of flowers dropped and distinctly different than the rest of the treatments (Table 5). The highest number of flowers dropped was expected due to the less effective pollination by insects caused by the shorter staminode to style distance $(\sim 1.83 \mathrm{~mm})$ in this KKM4 clone. Such gap of staminode to style is inaccessible for the entrance of main cocoa flower pollinator especially Forcipomyia spp. which have body length of between 2.00 to $3.00 \mathrm{~mm}[22,23]$. According to Frimpong et al. [3], a gap between staminode to style need to be in between 2.00 to $3.00 \mathrm{~mm}$ to guarantee the successful deposition of pollen grains onto a style of a receptive stigma. With the larger space in between the staminodes, this will help to provide mobility and intimate contact for the pollinators' thorax to dislodge pollen grains onto the style.

The number of pollinated flowers developed into young fruit also indicated a clone by propagation interaction. KKM4 clone of immature zygotic embryo culture observed with the lowest fruit development ( 5 fruits) due to the increased number of flowers ( 5 flowers) aborted after anthesis. Though, a small number of pollinated flowers developed into fruits is a common physiological characteristic of young 
cocoa plant [24-26]. Venturieri [27] reported that for crop species with fruits which are energetically expensive to produce such as cocoa, only few fruits will be produced. This is because the mother tree is physiologically unable to provide all the nutrient requirements for both flower and fruit growths [28].

Table 5 The number of flowers dropped within $48 \mathrm{~h}$ after anthesis and number of pollinated flowers developed into young fruit for all cocoa clones.

\begin{tabular}{|c|c|c|c|}
\hline $\begin{array}{l}\text { Cocoa } \\
\text { clones }\end{array}$ & Propagation type & $\begin{array}{l}\text { Number of flowers } \\
\text { dropped within } 48 \mathrm{~h} \\
\text { after anthesis } \\
\text { (\% in brackets) }\end{array}$ & $\begin{array}{l}\text { Number of pollinated } \\
\text { flowers developed } \\
\text { into young fruit } \\
\text { (\% in brackets) }\end{array}$ \\
\hline \multirow[t]{4}{*}{$\mathrm{MCBC} 1$} & ST & $4(40)$ & $6(60)$ \\
\hline & $\mathrm{IZ}$ & $4(40)$ & $6(60)$ \\
\hline & $\mathrm{G}$ & $4(40)$ & $6(60)$ \\
\hline & Mean & $4(40)$ & $6(60)$ \\
\hline \multirow[t]{4}{*}{ PBC230 } & ST & $4(40)$ & $6(60)$ \\
\hline & $\mathrm{IZ}$ & $4(40)$ & $6(60)$ \\
\hline & $\mathrm{G}$ & $4(40)$ & $6(60)$ \\
\hline & Mean & $4(40)$ & $6(60)$ \\
\hline \multirow[t]{4}{*}{ KKM22 } & ST & $4(40)$ & $6(60)$ \\
\hline & $\mathrm{IZ}$ & $4(40)$ & $6(60)$ \\
\hline & G & $4(40)$ & $6(60)$ \\
\hline & Mean & $4(40)$ & $6(60)$ \\
\hline \multirow[t]{10}{*}{ KKM4 } & $\mathrm{ST}$ & $4(40)$ & $6(60)$ \\
\hline & $\mathrm{IZ}$ & $5(50)$ & $5(50)$ \\
\hline & $\mathrm{G}$ & $4(40)$ & $6(60)$ \\
\hline & Mean & $4(40)$ & $6(60)$ \\
\hline & $p$-value for propagation & 0.701 & 0.766 \\
\hline & Tukey HSD (5\%) & 0.54 & 0.43 \\
\hline & $p$-value for clones & 0.855 & 0.880 \\
\hline & Tukey HSD (5 \%) & 0.54 & 0.39 \\
\hline & $p$-value for propagation*clones & $<0.05$ & $<0.05$ \\
\hline & Tukey HSD (5 \%) & 0.88 & 0.82 \\
\hline
\end{tabular}

ST, staminode culture trees; IZ, Immature zygotic embryo culture trees; G, Grafted trees; Tukey HSD, Tukey honestly significance difference.

\section{Floral development scale}

The comprehensive assessment on floral development showed the ontogenetical changes from inflorescence emergence to full flower open. The transition process from the FBV (BBCH51) to the completion of bud growth (BBCH59) required $\sim 30$ days with no difference between somatic embryogenesis cultured and grafted clones (Table 6). This result is similar with those found by Niemenak et al. [7] and Bridgemohan et al. [8] for seed, rooted cutting and grafted cocoa clones from Caribbean, i.e. Jamaica and Trinidad and Tobago. The first sign of flower initiation marked by the emergence of bud primordia (BBCH51) on the stem and jorquette branches (Figure 1). The bud primordia continuously expanded with subsequent sepal formation (BBCH52). The sepals then grew and enclosed the flower bud (BBCH55). The following stage (BBCH56) observed with the production and growth of pedicle. At stage $\mathrm{BBCH} 58$, the flower bud changed in the color from greenish yellow $(7.5 \mathrm{Y} 8 / 4)$ to yellow $(5.0 \mathrm{Y}(8 / 8$ to $8 / 10)$ ). The formation of 5 longitudinal abscission zones from the tip to the base of the floral bud represented the completion of inflorescence emergence (BBCH59). Congruent with those reported by Niemenak et al. [7], the sepal was relatively thick and embodied half of the total thickness of the developing flower during flower bud final growth. All these characteristics of flower bud conformed the production of true to type somatic embryogenesis cultured clones in this study. Similar with cocoa, other Theobroma species such as T. speciosum [29] and T. Subincanum [11,15] were also observed with the similar characteristics of inflorescence emergence. 
Table 6 Numbers of days from FBV (BBCH 51) to the completion of bud growth (BBCH 59) for all cocoa trees.

\begin{tabular}{cccccc}
\hline \multirow{2}{*}{ Propagation type } & \multicolumn{5}{c}{ Number of days from FBV to the completion of bud growth } \\
\cline { 2 - 6 } & MCBC1 & PBC230 & KKM22 & KKM4 & Mean \\
\hline ST & 29.7 & 30.1 & 29.7 & 29.6 & 29.8 \\
IZ & 30.2 & 29.5 & 29.9 & 29.7 & 29.8 \\
G & 29.4 & 29.7 & 29.4 & 29.7 & 29.6 \\
\hline Mean & 29.8 & 29.8 & 29.7 & 29.7 \\
\hline$p$-value & Propagation & Clone & Propagation*clone \\
\hline Tukey HSD (5\%) & 0.845 & 0.976 & \multicolumn{3}{c}{0.761} \\
\hline
\end{tabular}

ST, staminode culture trees; IZ, Immature zygotic embryo culture trees; G, Grafted trees, FBV = First bud visible.
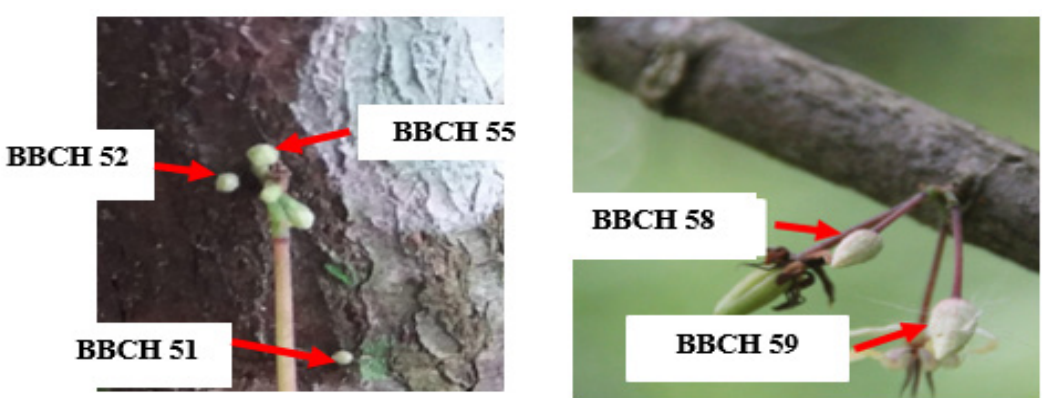

Figure 1 Illustration of inflorescence emergence showing BBCH $51=$ Flower bud visible, $\mathrm{BBCH} 52=$ flower bud expanded and sepal formed, BBCH $55=$ sepal enclosed bud, BBCH $56=$ emergence of flower pedicle, $\mathrm{BBCH} 58$ = flower bud expanded and changed colour and $\mathrm{BBCH} 59=$ bud growth complete.

Following the completion of bud growth, flower opening phase (dehiscing) initiated by the separation of longitudinal abscission zones. The separation process produced 5 individual sepals (BBCH61). A detail observation found that both sepals and petals opened outward simultaneously within $12 \mathrm{~h}$ (Figure 2). Similar with cocoa clones of Trinitario variety from Caribbean [7], the sepals were started to open during afternoon at day 30 after FBV. When $10 \%$ of the sepals opened at $3 \mathrm{pm}$, this indicated stage BBCH62. From BBCH63 to BBCH64, about $25 \%$ of flowers opened at 6 pm after 30 days from the FBV (BBCH51). The flower was continuously opened throughout night and when $80 \%$ of flower have opened, the stage was BBCH68. This stage which were not described by Niemenak et al. [7] and Bridgemohan et al. [8] can be added to the $\mathrm{BBCH}$ scale for a future reference of clones from the Trintario variety in Asia. At 10 am after 31 days from FBV, all cocoa flowers were fully opened.
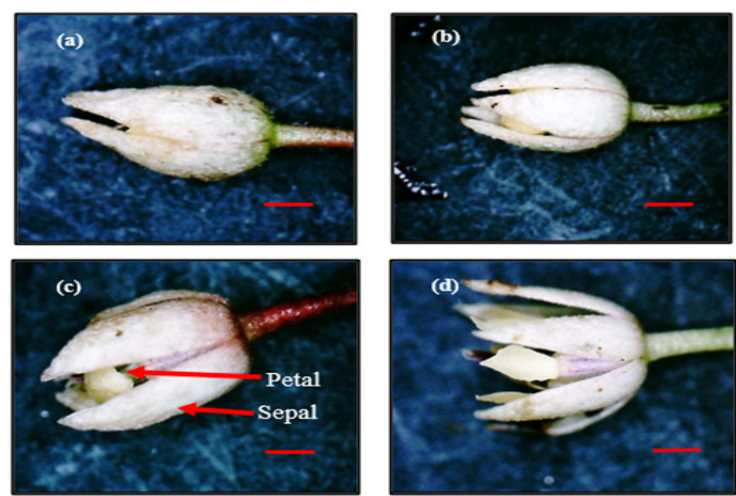

Figure 2 The stages of flower opening phase at day-30 and 31 after FBV. a) BBCH $62=10 \%$ of flower open ( $3 \mathrm{pm}$, day-30), b) BBCH 63 to BBCH $64=25 \%$ of flower open ( $6 \mathrm{pm}$, day-30), c) BBCH $65=50$ $\%$ of flower open (10 pm, day-30) and d) BBCH $68=80 \%$ of flower open $(6$ am, day-31). Red bar $=2.0$ $\mathrm{mm}$. 


\section{Stigmatic receptivity}

The anthesis process of all cocoa flower begun in the morning after 31 days from the appearance of the first bud. From observation, the stigma become receptive soon at 10 am after the anthesis. The intensity of the stigmatic receptivity increases in the evening $(5 \mathrm{pm})$ to its highest level in the next morning $(10 \mathrm{am})$ and then it decreased in the afternoon (Table 7). The positive esterase and peroxidase activities on the stigma indicated by the presence of compact bubbles on the entire surface of $\mathrm{H}_{2} \mathrm{O}_{2}$ solution (Figure 3). The active activities of both isoenzymes were the best indicators of the cocoa flower readiness for the subsequent pollination process. The reduction in the appearance of compact bubbles less than $1 \mathrm{~min}$ at $5 \mathrm{pm}$ on the second day (day-32) indicated the end of flower anthesis phase. The cocoa flowers receptivity for $48 \mathrm{~h}$ indicated a 2 days period of anthesis.

In Theobroma species such as T. subincanum [15], the timing of stigmatic receptivity was almost similar with $T$. cacao. The maximum intensity of stigmatic receptivity for the species was found from 10 am on the first day to $2 \mathrm{pm}$ of second day after anthesis. Contradictorily, the maximum intensity of stigmatic receptivity observed late at $6 \mathrm{pm}$ on the first day of anthesis for both $T$. obovatum and $T$. speciosum $[11,29]$. The findings from these studies showed variation in the definite period of optimum stigmatic receptivity in Theobroma genus. Comparable with flower development, no study has been conducted on the stigmatic receptivity of cocoa clones in Asia. Such study is imperative because after pollination, the cocoa flower fertilization process will only be effective when pollen develops its tube under receptive stigmatic surface [30].

Table 7 The intensity of stigmatic receptivity for all cocoa clones during anthesis.

\begin{tabular}{|c|c|c|c|c|}
\hline \multirow[b]{2}{*}{ Stigmatic receptivity } & \multicolumn{4}{|c|}{ Duration of flower anthesis } \\
\hline & $\begin{array}{l}1^{\text {st day }} \\
10 \text { am }\end{array}$ & $\begin{array}{c}1^{\text {st }} \text { day } \\
5 \mathrm{pm}\end{array}$ & $\begin{array}{c}2^{\text {nd day }} \text { da } \\
10 \text { am }\end{array}$ & $\begin{array}{c}2^{\text {nd day }} \\
5 \mathrm{pm}\end{array}$ \\
\hline Intensity of stigmatic receptivity & + & ++ & +++ & + \\
\hline Categorisation of the receptive period & ARP & ARP & ARP & ARP \\
\hline
\end{tabular}

Intensity of stigmatic receptivity. $+=$ Low,$++=$ Moderate and $+++=$ High; ARP $=$ Active receptive period.
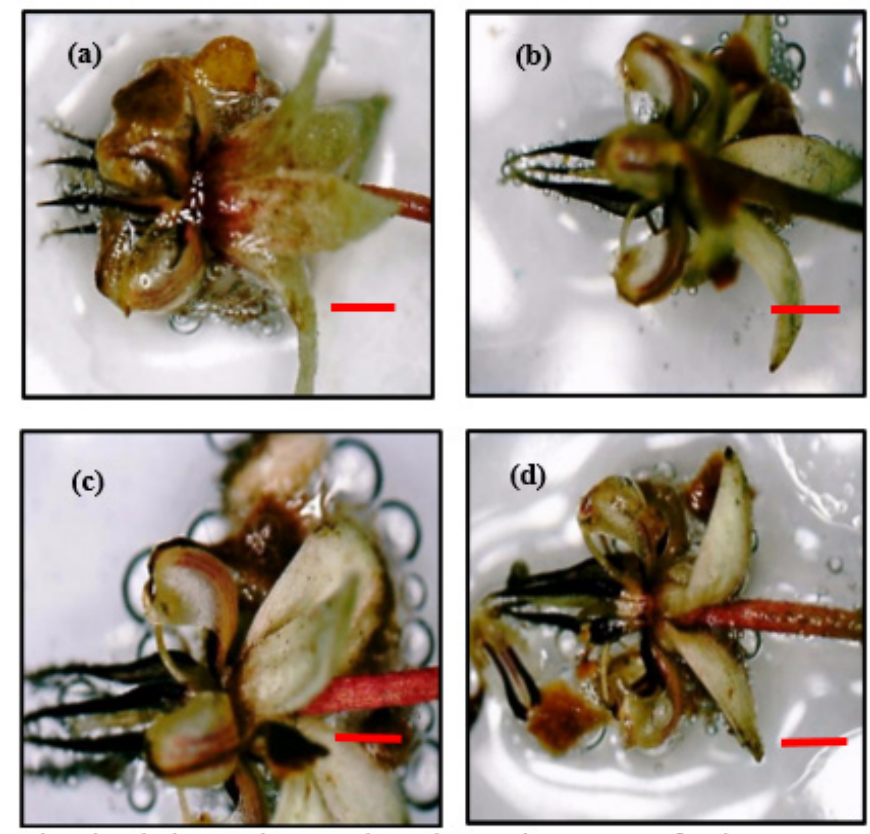

Figure 2 The visual observation on stigmatic reaction to $\mathrm{H}_{2} \mathrm{O}_{2}$ solution by the appearance of bubbles at different time during anthesis. (a) $1^{\text {st }}$ day at $10 \mathrm{am}$, (b) $1^{\text {st }}$ day at $5 \mathrm{pm}$, (c) $2^{\text {nd }}$ day at 10 am and (d) $2^{\text {nd }}$ day at $5 \mathrm{pm}$. Red bar $=2.0 \mathrm{~mm}$. 


\section{Conclusions}

Cocoa clones propagated from somatic embryogenesis culture exhibited true to type reproductive characteristics similar with conventional grafted clones. Though, KKM4 clone propagated from immature zygotic embryo culture produced the shortest staminode to style distance and this has caused a reduction in the flower stability. This KKM4 clone observed with the higher number of flower losses and lower fruit production. The photographic illustrations of flower development are important to help the agronomist for the identification of the main stages involved during cocoa plant 31 days of reproductive cycle. This enable a communication with farmers to decide the best management during the critical flowering period. The stigmatic receptivity of all cocoa clones which occurred for 2 days provided an information on the timing of flower readiness for the subsequent pollination process.

\section{Acknowledgements}

This study was funded by Universiti Malaysia Sarawak (UNIMAS) internal grant under the PhD Student Fund (Grant No. F07/DPP/1596/2017). The authors are grateful to the staffs at Malaysian Cocoa Board for their technical assistance.

\section{References}

[1] T Mabbett. Midges the insect key to cocoa pollination. Cocoa Coffee Int. Issue 1989; 4, 56-65.

[2] M Adjaloo, BKB Banful and W Oduro. Evaluation of breeding substrates for cocoa pollinator, Forcipomyia spp. and subsequent implications for yield in a tropical cocoa production system. Am. J. Plant Sci. 2013; 4, 204-11.

[3] EA Frimpong, BG Herren, I Gordon and PK Kwapong. Dynamics of insect pollinators as influenced by cocoa production systems in Ghana. J. Pollinat. Ecol. 2014; 5, 74-80.

[4] DR Glendenning. Natural pollination of cocoa. New Phytol. 1972; 71, 719-29.

[5] T Kaufmann. Ecology and behaviour of cocoa pollinating Ceratopogonidae in Ghana, West Africa. Environ. Entomol. 1975; 4, 347-51.

[6] M Adjaloo, W Oduro and BK Banful. Floral phenology of upper Amazon Cocoa trees: Implications for reproduction and productivity of cocoa. Agronomy 2012; 20, 461674.

[7] N Niemenak, C Cilas, C Rohsius, H Bleiholder, U Meier and R Lieberei. Phenological growth stages of cacao plants (Theobroma sp.): Codification and description according to the BBCH Scale. Ann. Appl. Biol. 2010; 156, 13-24.

[8] P Bridgemohan, MES Mohamed, M Mohammed, K Singh, L Shamir and H Bridgemohan. The application of $\mathrm{BBCH}$ scale for codification and illustrations of the floral stages of Caribbean fine cacao (Theobroma cacao L.). J. Agr. Sci. Tech. 2016; 6, 1-10.

[9] A Bhattacharya and S Mandal. Pollination, pollen germination and stigma receptivity in Moringa oleifera Lamk. Grana 2004; 43, 48-56.

[10] K Dey, S Mondal and S Mandal. Studies on stigma receptivity of Grewia asiatica L. with reference to esterase and peroxidase activity. Int. J. Eng. Sci. 2016; 2, 120-28.

[11] MDA Souza, AAB Rossi, TTL Varella, GD Silveira and SAM Souza. Stigmatic receptivity and pollen viability of Theobroma subincanum Mart.: Fruit species from the Amazon region. Rev. Bras. Frutic. 2016; 38, 757-65.

[12] MW Bairu, AO Aremu and J Van Staden. Somaclonal variation in plants: Causes and detection methods. Plant Growth Regul. 2011; 63, 147-73.

[13] N Adrianti. 2013, Development of somatic embryogenesis and plant regeneration for selected Malaysian cocoa (Theobroma cacao L.) clones from immature zygotic embryo cultures. Master Thesis. Universiti Malaysia Sarawak, Sarawak, Malaysia.

[14] AD McKelvie. A list of mutant genes in Arabidopsis thaliana (L.) Heynh. Radiat. Bot. 1961; 1, 233-41.

[15] MDAD Souza, AAEB Rossi, TL Varella, GF Silveira and SAM Souza. Stigmatic receptivity and pollen viability of Theobroma subincanum Mart.: Fruit species from the Amazon region. Rev. Bras. Frutic. 2016; 3, 757-64.

[16] AP Dafni. Pollination ecology - a practical approach. Oxford University Press, New York, 1992.

[17] L Lowry. VassarStats: Website for statistical computation, Available at: http://vassarstats.net/, accessed May 2018.

[18] KF Anin, M Adjaloo, PK Kwapong and W Oduro. Structure and stability of cocoa flowers and their response to pollination. J. Bot. 2014; 14, 5-10. 
[19] GC Mgbeze and A Iserhienrhien. Somaclonal variation associated with oil palm (Elaeis guineensis Jacq.) clonal propagation: A review. Afr. J. Biotechnol. 2014; 13, 989-97.

[20] JI Zebrowska. Effect of quantitative plant traits on the efficiency of in vitro cloning of strawberry (Fragaria x Ananassa Duch.). J. Hortic. Sci. Biotech. 2015; 90, 407-12.

[21] S Sarmah, S Kolukunde, M Sutradhar, BK Singh, T Mandal and N Mandal. A review on: In vitro cloning of orchids. Int. J. Curr. Microbiol. Appl. Sci. 2017; 6, 1909-27.

[22] A Ghani Ibrahim and AM Hussein. Role of insects in the pollination of cocoa flowers. Pertanika 1987; 10, 103-6.

[23] B Saripah and A Alias. The use of transferable breeding container for population enrichment of pollinator, Forcipomyia spp. in the cocoa ecosystem. J. Adv. Agric. Tech. 2018; 5, 245-51.

[24] PT Alvim. Flowering of cocoa. Cocoa Growers' Bulletin 1984; 35, 23-31.

[25] JCN Zi, J Kahia, L Diby and C Kouame. Compatibility of ten elite cocoa (Theobroma cacao L.) clones. Sci. Hortic. 2017; 3, 45.

[26] M Aneja, T Gianfagna and E Ng. The roles of abscisic acid and ethylene in the abscission and senescence of cocoa flowers. Plant Growth Regul. 1999; 27, 149-55.

[27] GA Venturieri. Flowering levels, harvest season and yields of cupuassu (Theobroma grandiflorum). Acta Amazonicas 2011; 41, 143-52.

[28] AG Stephenson. Flower and fruit abortion: Proximate causes and ultimate functions. Annu. Rev. Ecol. Evol. Syst. 1981; 12, 253-79.

[29] MS Souza and AG Venturieri. Floral biology of cacauhy (Theobroma speciosum - Malvaceae). Braz. Arch. Biol. Tech. 2010; 53, 861-72.

[30] S Royaert, W Phillips-Mora and AMA Leal. Identification of marker-trait associations for selfcompatibility in segregating mapping population of Theobroma cacao L. Tree Genet. Genomes 2010; 7, 1159-68. 